\title{
S-100B and neuron specific enolase are poor outcome predictors in severe traumatic brain injury treated by an intracranial pressure targeted therapy
}

M Olivecrona, M Rodling-Wahlström, S Naredi, et al.

J Neurol Neurosurg Psychiatry 2009 80: 1241-1248 originally published online July 13, 2009

doi: 10.1136/jnnp.2008.158196

Updated information and services can be found at:

http://jnnp.bmj.com/content/80/11/1241.full.html

These include:

References This article cites 39 articles, 6 of which can be accessed free at: http://jnnp.bmj.com/content/80/11/1241.full.html\#ref-list-1

Email alerting Receive free email alerts when new articles cite this article. Sign up in the service box at the top right corner of the online article.

Topic collections Articles on similar topics can be found in the following collections

Coma and raised intracranial pressure (2639 articles)

Neurological injury (1765 articles)

Trauma CNS / PNS (1911 articles)

Trauma (12250 articles)

Injury (11467 articles)

\section{Notes}

To order reprints of this article go to:

http://jnnp.bmj.com/cgi/reprintform

To subscribe to Journal of Neurology, Neurosurgery \& Psychiatry go to: 


\title{
S-100B and neuron specific enolase are poor outcome predictors in severe traumatic brain injury treated by an intracranial pressure targeted therapy
}

\author{
M Olivecrona, ' M Rodling-Wahlström, ${ }^{2}$ S Naredi, ${ }^{2}$ L-0 D Koskinen'
}

\begin{abstract}
${ }^{1}$ Department of Pharmacology and Clinical Neurosciences, Division of Neurosurgery, Umeå University Hospital, Umeå, Sweden; ${ }^{2}$ Department of Surgical and Perioperative Sciences, Division of Anaesthesiology, Umeå University Hospital, Umeå, Sweden
\end{abstract}

Correspondence to: Dr M Olivecrona, Department of Neurosurgery, University Hospital, SE 90185 Umeå, Sweden;

magnus.olivecrona@vll.se

Received 14 July 2008 Revised 4 May 2009 Accepted 29 May 2009 Published Online First 13 July 2009

\section{ABSTRACT \\ Objective: To prospectively study S-100B and neuron specific enolase (NSE) levels in subjects treated for severe head injury (sTBI), and investigate the prognostic value of these biomarkers.}

Methods: Subjects included in a prospective double blind randomised study for sTBI. Inclusion criteria: Glasgow Coma Score (GCS) $\leqslant 8$, age 15-70 years, first recorded cerebral perfusion pressure of $>10 \mathrm{~mm} \mathrm{Hg}$ and arrival $<24 \mathrm{~h}$ after trauma. Subjects were treated with an intracranial pressure (ICP) targeted therapy. Blood samples for S-100B and NSE were drawn immediately after arrival and every $12 \mathrm{~h}$ for 5 days. Outcome was evaluated as Glasgow Outcome Scale (GOS) by independent staff at 3 and 12 months.

Results: 48 subjects, mean age 35.5 years, and median GCS 6 were included. The first blood sample was drawn at $15.6(1.4) \mathrm{h}$ after injury. Initial concentration of S-100B was $1.04(0.21) \mu \mathrm{g} / \mathrm{l}$ and for NSE 18.94 (2.32) $\mu \mathrm{g} / \mathrm{l}$. The biomarkers were significantly higher in subjects with GCS 3 and in those who died compared with those with GCS 4-8 and GOS 2-5, respectively. Receiver operated characteristic curve analyses of the initial S-100B and NSE levels to GOS dichotomised as unfavourable (GOS 13) and favourable (GOS 4-5) showed a weak correlation: AUC 0.585 and 0.555 , respectively. Using the dichotomisation dead (GOS 1)/alive (GOS 2-5), the AUC values were 0.687 and 0.734 , respectively. Furthermore, a correlation was found between the biomarkers themselves and the biomarkers and ICP.

Conclusion: At 3 and 12 months after trauma, no differences in prognostic values between the markers were apparent nor was there any clinical significant value of the markers as predictors of clinical outcome.

Over the past decades there has been a rising interest in biochemical markers. They are used for diagnosis of many disorders, including: myocardial infarction (troponin), renal failure (creatinine), acute pancreatitis (amylase) and malignant diseases (prostate specific antigen, $\alpha$-phoeto protein). One of the first substances studied as a biochemical marker of cerebral injury in the clinical setting was CK-BB. ${ }^{12}$ Today, several biochemical markers for brain injury have been evaluated for clinical use. The studies have mostly aimed at finding reliable biochemical markers for brain injury which would allow for discrimination between potentially serious and potentially non-serious head injury, mostly defined as findings on CT scan..$^{3-5}$ Other studies have focused on the prediction of outcome after head injury. ${ }^{67}$ Among the recent most intensely studied biochemical markers are S-100B and neuron specific enolase (NSE).

$\mathrm{S}-100 \mathrm{~B}$ is a small calcium binding protein found in the astroglial cells and in Schwann cells. ${ }^{8} 9$ It has been shown that the concentration of this protein increases in CSF and serum after cerebral injuries such as: head injury, meningitis, subarachnoid haemorrhage and stroke. ${ }^{10} 11$ However, increased levels of S-100B can also be detected after extracranial injuries (eg, coronary bypass surgery and fractures of long bones). ${ }^{12-14} \mathrm{~S}-100 \mathrm{~B}$ is metabolised in the kidney and excreted in urine. The biological half-time of S-100B is estimated to be less than 30 min. ${ }^{15}{ }^{16}$ Nonetheless, other values for the halftime have been reported. ${ }^{17} 18$

NSE is located in the cytoplasm of neurons and is a glycolytic enzyme, involved in increasing the neuronal chloride levels during onset of neuronal activity. There is also a high amount of NSE in red blood cells and platelets. ${ }^{19}$ The biological half-time of NSE is estimated to be approximately $30 \mathrm{~h} .{ }^{19}$ Thus initial NSE levels are less sensitive to time elapsed since the trauma than S-100B levels.

Severe traumatic brain injury (sTBI) has been treated in our department since the early 1990s with an intracranial pressure (ICP) guided proto$\mathrm{col}^{20-22}$ These guidelines are based on the principles for treatment of sTBI published by Asgeirsson et al in $1994 .{ }^{23}$

This is a prospective study of subjects with sTBI treated following our ICP targeted protocol and in whom the S-100B and NSE samples were collected systematically. The specific aims of the present study were: to study the changes in S-100B and NSE concentrations over time; to study how the initial levels of S-100B and NSE correlate with the initial Glasgow Coma Score (GCS), ICP and clinical outcome, measured as Glasgow Outcome Scale (GOS); to investigate if the initial concentration of S-100B and NSE can predict clinical outcome, as measured by GOS; and finally, to study the relationship between the markers.

\section{MATERIAL AND METHODS}

\section{Subjects}

All subjects with sTBI admitted to our department between 1 January 2002 and 31 December 2005 were eligible for inclusion in the study, irrespective of clinical status or concomitant injury or disease. The subject cohort was part of a prospective randomised double blind study described previously. ${ }^{20}$

Inclusion criteria were: verified head injury, GCS $\leqslant 8$ at the time of sedation and intubation, age 
between 15 and 70 years, initial cerebral perfusion pressure (CPP) of $\geqslant 10 \mathrm{~mm} \mathrm{Hg}$ and arrival in our department within $24 \mathrm{~h}$ of the trauma. Excluded were subjects with penetrating head injuries, and pregnant or breastfeeding women. Subjects with an initial CPP $<10 \mathrm{~mm} \mathrm{Hg}$ were regarded as dead on arrival. Subjects who died within the first 3 months of inclusion in the study were regarded as mortality cases.

\section{Treatment}

The ICP targeted treatment protocol used in these subjects has been described thoroughly in previous publications. ${ }^{20}{ }^{22}$ In short, all subjects were sedated to a comfortable level, allowing them to cough, using midazolam and fentanyl. Subjects were all mechanically ventilated $\left(\mathrm{PaO}_{2} \geqslant 12 \mathrm{kPa}\right.$ and $\mathrm{PaCO}_{2}$ 4.5$5.5 \mathrm{kPa}$ ). ICP was measured continuously using a intraparenchymal pressure measuring device (Codman MicroSensor; Johnson \& Johnson Professional Inc, Raynham, Massachusetts, USA). ${ }^{24}$ Mass lesions were treated aggressively with surgery. Maintenance of normovolaemia and a normal colloid osmotic pressure was important and achieved by infusion of packed red blood cells, albumin, Ringer's acetate and glucose solutions. A neutral fluid balance was the goal, and furosemide was used when indicated. After establishment of normovolaemia, clonidine and metoprolol were given as intravenous infusions in order to normalise arterial blood pressure, so reducing the transcapillary hydrostatic pressure. These drugs also reduce the general level of stress mediated by the sympathetic nervous system. Further steps in the treatment as responses to a rising ICP were: additional sedation with low dose thiopental, placement of a ventriculostomy for the drainage of CSF and unilateral or bilateral hemicraniectomy with dura plasty.

\section{S-100B and NSE}

Blood for analysis of S-100B and NSE was sampled twice daily during the first 5 days. The first sample was drawn as soon as possible after the arrival of the subject in our department. Serum was frozen, stored in a $-70^{\circ} \mathrm{C}$ freezer. Serum samples were analysed in two batches with duplicated values. The method used for analysis was the fully automised Liason system, using the Liason Sangtec 100 assay for the S-100B and the Liason NSE assay for the analysis of NSE (AB DiaSorin; Sangtec Medical, Bromma, Sweden). S-100B analysis is an immunoluminometric method. The detection limit for S-100B is $0.02-30 \mu \mathrm{g} / \mathrm{l}$. Typical intra- and inter-assay variations are below $5 \%$ and $10 \%$, respectively. The cut-off level in healthy blood donors has been found to be $0.15 \mu \mathrm{g} / 1$ for the 95 th percentile, according to the manufacturers. NSE analysis used an immunoluminometric assay which measures levels between 0.04 and $200 \mu \mathrm{g} / \mathrm{l}$. Intra- and inter-assay variations are below $3 \%$ and $6 \%$, respectively. A level of NSE exceeding $10 \mu \mathrm{g} / 1$ has been considered to be pathological. ${ }^{25}$

\section{Outcome}

Outcome at 3 and 12 months after trauma was systematically evaluated as GOS, through structured interviews by independent staff following the guidelines for GOSE. Outcome is reported as GOS.

\section{Statistics}

Values are reported as mean (SEM) or, in case of discrete variables, as median (range). ANOVA with the Bonferroni post hoc test and Student's two tailed t test were used for calculation of significant differences between the means. Bivariate Pearson correlation analysis was applied as indicated. For the prediction of outcome in relation to the markers, receiver operated characteristic (ROC) curve analysis was used. For statistical analyses, the commercial statistical software packages JMP V.5.0 (SAS Institute Inc) program and MedCalc program V.9.6.00 were used. A p value $\leqslant 0.05$ was considered statistically significant.

The study was approved by the local ethics committee at Umeå University Hospital (dnr 00-175).

\section{RESULTS}

Forty-eight subjects were included in the study. The female/ male ratio was $17 / 31$. Basic data on patients and outcome are presented in table 1 . Table 1 shows the clinical outcome at 3 and 12 months. Mortality at 3 and 12 months was $12.5 \%$ and $16.7 \%$, respectively, and the corresponding favourable outcome (GOS 3-5) values were $52.1 \%$ and $58.3 \%$, respectively. When excluding subjects with GCS 3 and/or bilaterally dilated fixed pupils, mortality was $0 \%$ and favourable outcome $61 \%$ at 3 months. Only two subjects died during the time of treatment in our department, both due to therapy refractive high ICP. Thus $95.8 \%$ of subjects treated were discharged alive from our department after stabilisation of ICP to levels below $20 \mathrm{mmHg}$.

The first sample for analysis of the biomarkers was collected at a mean of 15.6 (1.4) h (median 14.5, range 6-37 h) after injury. Mean concentration of S-100B in the first sample was

Table 1 Characteristics of included patients and outcome according to Glasgow Outcome Scale at 3 and 12 months

\begin{tabular}{|c|c|}
\hline Characteristic & \\
\hline \multicolumn{2}{|l|}{ Age } \\
\hline Mean (SEM) & $35.5(2.2)$ \\
\hline Median (range) & $30.5(15-63)$ \\
\hline \multicolumn{2}{|l|}{ GCS } \\
\hline Mean (SEM) & $5.3(0.2)$ \\
\hline Median (range) & $6(3-8)$ \\
\hline \multicolumn{2}{|l|}{ ISS } \\
\hline Mean (SEM) & $28.8(1.4)$ \\
\hline Median (range) & $29(9-50)$ \\
\hline \multicolumn{2}{|l|}{ APACHE ॥ } \\
\hline Mean (SEM) & $20.8(0.7)$ \\
\hline Median (range) & $20.5(12-32)$ \\
\hline Time from accident until admission (mean (SEM)) & $6.2(0.7)$ \\
\hline \multicolumn{2}{|l|}{ Radiological classification according to Marshall|l ${ }^{39}(\%)$} \\
\hline Diffuse Injury I & 4.2 \\
\hline Diffuse Injury II & 18.8 \\
\hline Diffuse Injury III & 33.3 \\
\hline Diffuse Injury IV & 6.3 \\
\hline Non-evacuated mass lesion & 37.5 \\
\hline \multicolumn{2}{|l|}{ Outcome } \\
\hline GOS at 3 months (median (range)) & $4(1-5)$ \\
\hline GOS at 12 months (median (range)) & $4(1-5)$ \\
\hline \multicolumn{2}{|l|}{ Dichotomised outcome at 3 months (\%) } \\
\hline Mortality 3 months (GOS 1) & 12.5 \\
\hline Unfavourable outcome 3 months (GOS 2-3) & 35.4 \\
\hline Favourable outcome 3 months (GOS 4-5) & 52.1 \\
\hline \multicolumn{2}{|l|}{ Dichotomised outcome at 12 months (\%) } \\
\hline Mortality 12 months (GOS 1) & 16.7 \\
\hline Unfavourable Outcome 12 months (GOS 2-3) & 25.0 \\
\hline Favourable outcome 12 months (GOS 4-5) & 58.3 \\
\hline
\end{tabular}

Findings on the initial CT scan were classified according to Marshall and colleagues. ${ }^{39}$ APACHE II, Acute Physiology and Chronic Health Evaluation II; GCS, Glasgow Coma Scale; GOS, Glasgow Outcome Scale; ISS, Injury Severity Score. 


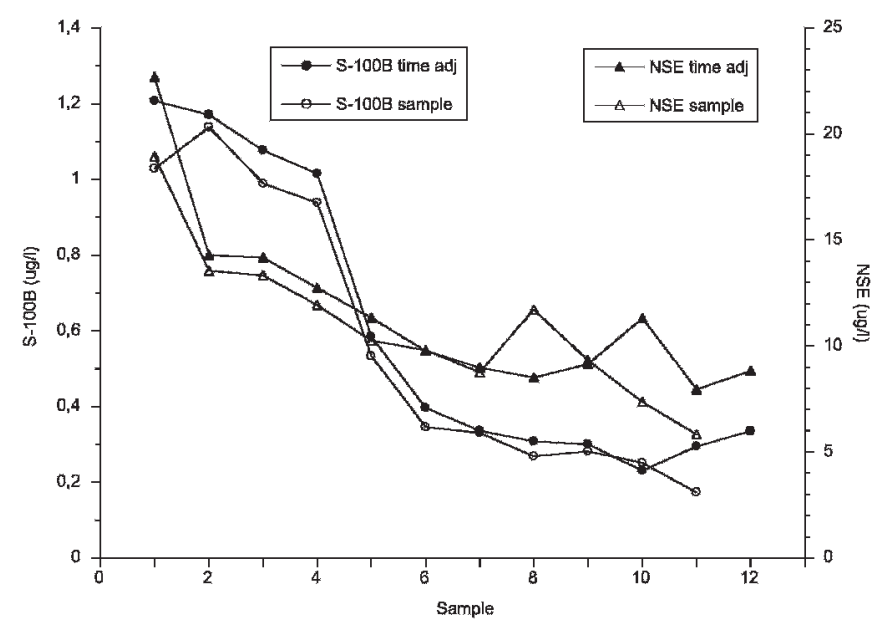

Figure 1 Mean concentrations of S-100B and neuron specific enolase (NSE) over time, sample for sample and time adjusted to the nearest $12 \mathrm{~h}$ period after trauma.

$1.04(0.21) \mu \mathrm{g} / \mathrm{l}$. The corresponding value for NSE was 18.94 (2.32) $\mu \mathrm{g} / \mathrm{l}$. The change in S-100B levels over time is shown in fig 1. Figure 1 depicts the changes between the samples and changes in S-100B values in a time adjusted manner. Time after trauma was categorised into $12 \mathrm{~h}$ intervals, and samples allocated to the $12 \mathrm{~h}$ point closest to the actual sample time after trauma. As shown, there was a gradual decline in concentrations over time. Change over time in NSE concentrations is shown in fig 1. Figure 1 also depicts values adjusted for time in the same manner as described above.

Figures 2 and 3 show the initial concentration of S-100B in relation to GCS and GOS, respectively. In patients with GCS 3 , S-100B was clearly higher compared with GCS 4-8 $(p<0.01$, ANOVA with Bonferroni post hoc test). A similar pattern was found in patients with GOS 1 at 3 and 12 months (dead) compared with GOS 2-5 ( $p<0.01$, ANOVA with Bonferroni post hoc test). There was no statistically significant difference in S-100B levels when results were dichotomised into unfavourable (GOS 1-3) and favourable (GOS 4-5) outcome. A similar pattern was observed for NSE (fig 2, 3). In fig 4, a scatterplot of individual initial S-100B values is shown in relation to outcome at 3 and 12 months.

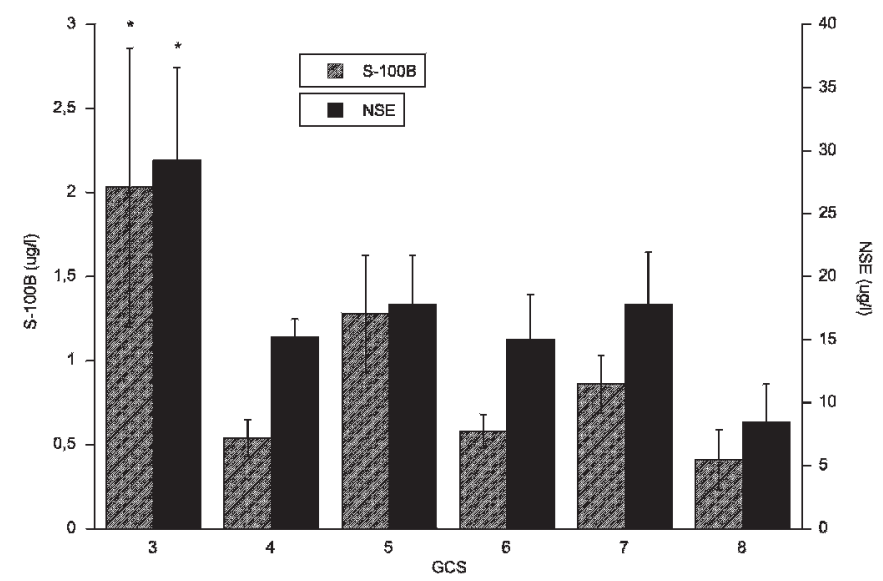

Figure 2 Initial concentration of S-100B and neuron specific enolase (NSE) in relation to Glasgow Coma Score (GCS) at intubation and sedation ( ${ }^{*} p \leqslant 0.01$, ANOVA with Bonferroni post hoc test).

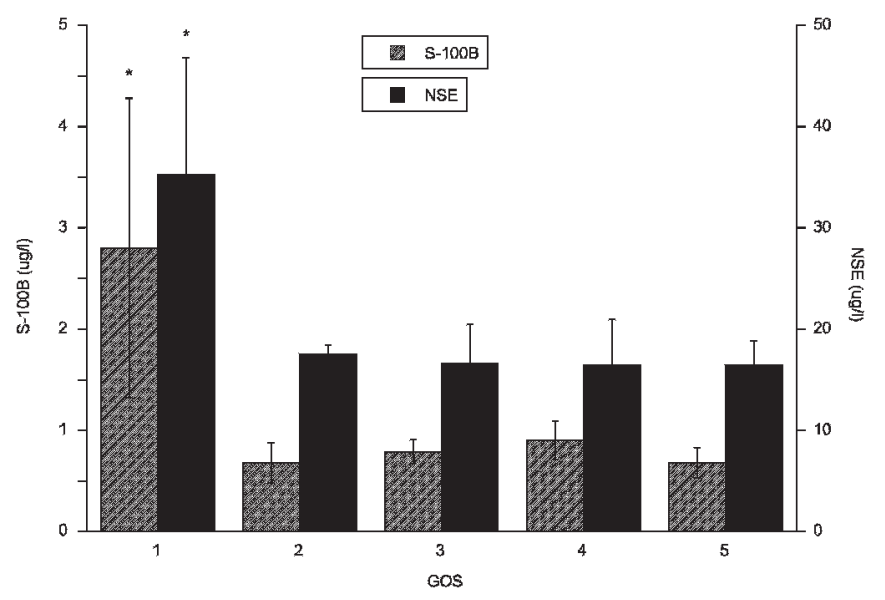

Figure 3 Initial concentration of S-100B and neuron specific enolase (NSE) in relation to Glasgow Outcome Scale (GOS) at 3 and 12 months after injury ( ${ }^{*} p \leqslant 0.01$, ANOVA with Bonferroni post hoc test).

In fig 5, the correlation between the initial time adjusted S-100B and NSE value to the time adjusted mean ICP during the first $12 \mathrm{~h}$ period is depicted. As shown in fig 5, there was a significant correlation $(R=0.64, p \leqslant 0.0001$ and $R=0.57$, $\mathrm{p} \leqslant 0.0001$, respectively) between the parameters. If analysing all values for $\mathrm{S}-100 \mathrm{~B}$ and NSE in relation to ICP values during the 5 days, a significant correlation was found for both S-100B and NSE $(R=0.75, p<0.0001$ and $R=0.51, p<0.0001$, respectively).

Only two subjects were classified as Marshall I on the initial CT scan, indicating that all of the others had significant tissue damage. There was neither a statistically significant correlation between Marshall classification and the initial S-100B or NSE levels nor between the highest level of the biomarkers. However, the two subjects classified as Marshall I had lower levels of the biomarkers compared with the other patients.

A secondary increase in S-100B and NSE was observed in seven subjects. These secondary increases were not associated with GOS at 3 months or ICP, except in the two subjects that died during ICU treatment. Outcome at 3 months was in the

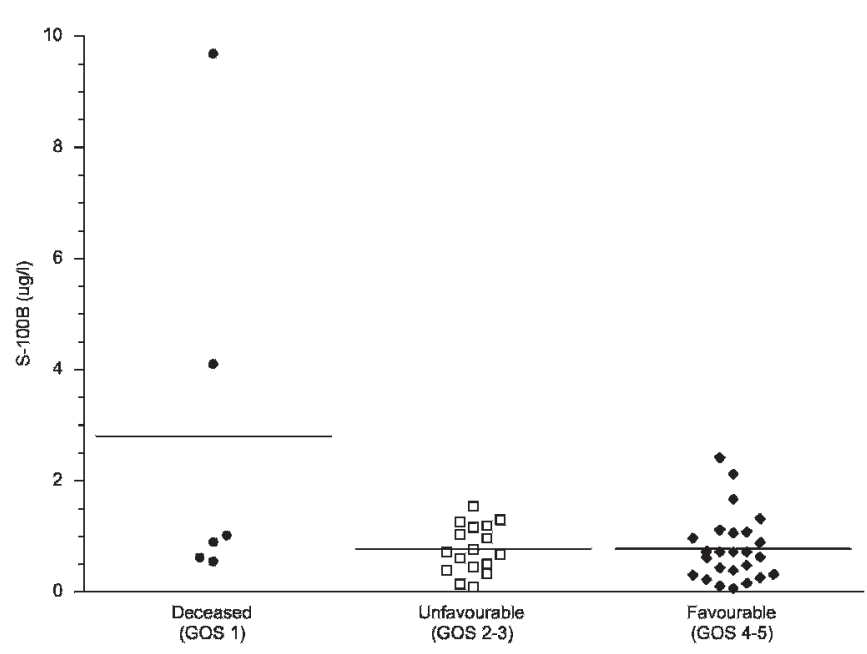

Figure 4 Scatterplot of individual initial S-100B values in relation to Glasgow Outcome Scale (GOS) at 3 and 12 months. Observe that the unfavourable group is split into GOS 1 and GOS 2-3. The horizontal line represents the mean initial S-100B concentration. 


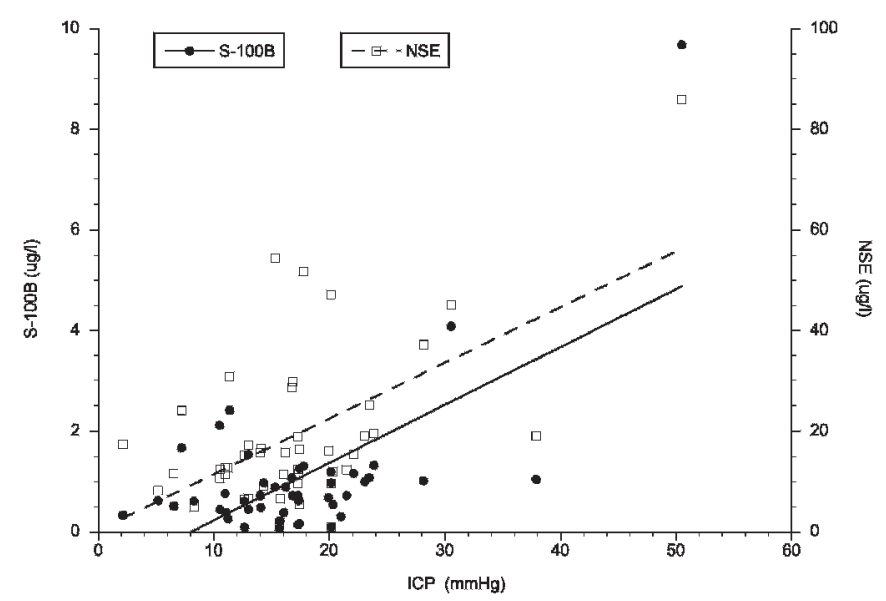

Figure 5 Correlation of the time adjusted $S-100 B(R=0.64$, $p \leqslant 0.0001$ ) and neuron specific enolase (NSE) levels ( $R=0.57$, $p \leqslant 0.0001$ ) with time adjusted intracranial pressure (ICP) values for the first $12 \mathrm{~h}$.

these seven subjects: GOS $1(n=2), \operatorname{GOS} 3(n=1)$, GOS 4 $(\mathrm{n}=2)$ and $\operatorname{GOS} 5(\mathrm{n}=2)$.

In fig 6 , the ROC curve of the initial concentrations of S-100B and NSE for the prediction of unfavourable outcome, defined as GOS 1-3, and favourable outcome (GOS 4-5) at 3 months, is depicted. A level of S-100B $>0.32 \mu \mathrm{g} / 1$ has the highest accuracy. The corresponding point for NSE level was $>9.52 \mu \mathrm{g} / \mathrm{l}$. As shown in table 2, the area under the curve (AUC) for both S-100B and NSE was close to 0.5, and thus no reliable conclusions can be drawn. If the prediction analysis used the dichotomisation of GOS in dead (GOS 1) and living (GOS 2-5) subjects (ie, prediction of mortality), the corresponding ROC analysis showed a larger AUC and thus a stronger prediction (table 2, fig 7). Using clinical outcome at 12 months and the same ROC curve analysis did not substantially improve the ability to predict outcome. Values are shown in table 2 .

If the aim were to use the initial concentrations of S-100B and NSE to predict whether or not to treat (ie, to predict death due to sTBI), the cut-off values of the markers would be $1.67 \mu \mathrm{g} / \mathrm{l}$ and $47.15 \mu \mathrm{g} / \mathrm{l}$, respectively (table 2 ). This analysis is based on the presumption that the test has to have a false positive rate of $5 \%$ or less (ie, $1 / 20$ subjects that would have been salvageable were left to die). The corresponding values using the outcome at 12 months are depicted in table 2.

There was a fairly good correlation between all S-100B and NSE levels $(R=0.63, p \leqslant 0.0001)$. Using only the first samples, the corresponding correlation was $R=0.75$ ( $p \leqslant 0.0001)$.

Pairwise comparison of the ROC analysis for S-100B and NSE showed no statistical significant difference in AUC in either the dead/alive group or the unfavourable/favourable group. The difference between the AUCs was 0.046 and 0.073 , respectively.

\section{DISCUSSION}

In the present study, we followed the time course of S-100B and NSE in subjects suffering from sTBI. This is the first study, as far as we know, which describe the temporal profile of markers in a cohort of subjects with sTBI treated by protocol, using an ICP targeted therapy based on the principles published by Asgeirsson et al in 1994. ${ }^{23}$ A strength of the study is that the concentrations of the markers were measured twice daily for 5 consecutive days. These subjects were severely ill, as shown not only by the low initial GCS but also by high ISS and APACHE II

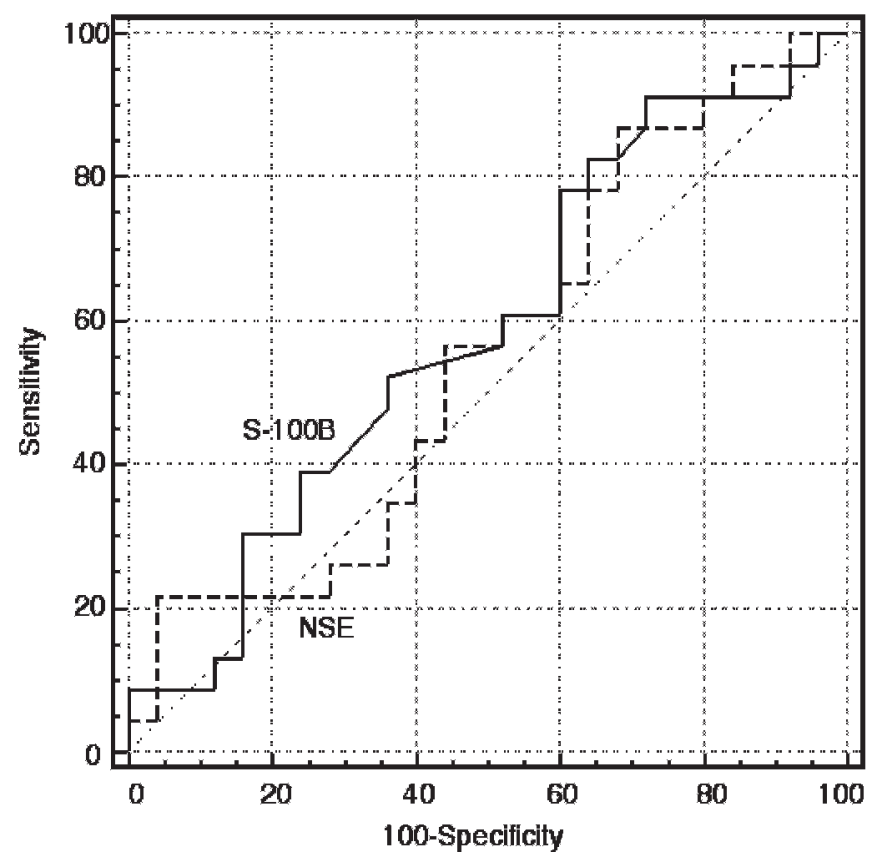

Figure 6 Receiver operated characteristic curve analysis of S-100B (AUC 0.585, $\mathrm{Cl} 0.434$ to 0.725 ) and neuron specific enolase (NSE) (AUC 0.555 , Cl 0.404 to 0.698 ) for the prediction of unfavourable outcome (Glasgow Outcome Scale 1-3).

scores. The study allowed for inclusion of subjects irrespective of clinical status as long as their initial measured CPP was above $10 \mathrm{~mm} \mathrm{Hg}$.

As expected, we found a decay in the level of the markers over time. In the literature we have found different half-times for $\mathrm{S}-100 \mathrm{~B}$, from less than 30 min to between 1.5 and $2 \mathrm{~h} .{ }^{15-18}$ Looking at the curve for S-100B it seems that the biological half-time, at least, must be much longer. This apparently longer half-time could either be interpreted as that the actual half-time published previously is not correct or that the release of S-100B is an ongoing process over time. However, from a study in subjects with mild head injuries and an exact known time point of trauma in combination with a single injury it can be postulated that the S-100B half-time must be longer that previously reported. ${ }^{26}$ Raabe discussed the possibility of a non-momentous release of S-100B. ${ }^{27}$ It is plausible that there is ongoing release of S-100B due to an ongoing pathological process in the injured brain.

Only in the group with an initial GCS of 3 were S-100B levels proven to be significantly higher compared with the rest of the GCS levels.

S-100B increases after mannitol infusion and blood-brain barrier disruption. The authors suggest that minor elevation of S-100B $(<0.34 \mu \mathrm{g} / \mathrm{l})$ would indicate blood-brain barrier opening without CNS damage and higher levels would indicate brain damage. $^{28} 29$ The persistent elevation of S-100B could thus indicate ongoing brain injury as well as dysfunction of the blood-brain barrier or a combination thereof.

In contrast with Woertgen et al, we have shown that there was a significant correlation between the first measured S-100B and NSE levels and mean ICP during the first $12 \mathrm{~h} .{ }^{30}$ Indeed, it has been shown in an experimental pig model that increasing ICP levels results in elevated S-100B. ${ }^{31}$

One would expect that the more severe the tissue damage, the higher the S-100B and NSE concentrations. Interestingly, we were unable to show a correlation between brain tissue damage 
Table 2 Receiver operated characteristic curve analysis of the prediction of unfavourable outcome (Glasgow Outcome Scale 1-3) and mortality (Glasgow Outcome Scale 1) by initial concentration of S-100B and neuron specific enolase at 3 and 12 months after trauma

\begin{tabular}{|c|c|c|c|c|c|c|c|c|c|}
\hline & Accuracy & $\begin{array}{l}\text { Cut-off } \\
\text { level }(\mu \mathrm{g} / \mathrm{l})\end{array}$ & $\begin{array}{l}\text { Sensitivity } \\
(\%)\end{array}$ & $\begin{array}{l}\text { Specificity } \\
(\%)\end{array}$ & AUC & SE & $95 \% \mathrm{Cl}$ & PPV & NPV \\
\hline \multicolumn{10}{|l|}{ S-100B } \\
\hline 3 months & Highest & & & & & & & & \\
\hline \multirow[t]{2}{*}{ Dead/alive } & & 0.51 & 100 & 38.1 & 0.687 & 0.127 & $0.536-0.812$ & 18.7 & 100.0 \\
\hline & Clinically acceptable & & & & & & & & \\
\hline Dead/alive & & 1.67 & 33.3 & 95.2 & 0.687 & 0.127 & $0.536-0.812$ & 50.0 & 90.9 \\
\hline \multirow[t]{2}{*}{ Dead/alive } & & 0.51 & 87.5 & 37.5 & 0.647 & 0.114 & $0.446-0.779$ & 21.9 & 93.7 \\
\hline & Clinically acceptable & & & & & & & & \\
\hline Dead/alive & & 1.67 & 25.0 & 95.0 & 0.647 & 0.114 & $0.496-0.779$ & 50.0 & 86.4 \\
\hline \multicolumn{10}{|l|}{ Neuron specific enolase } \\
\hline 3 months & Highest & & & & & & & & \\
\hline Unfavourable/favourable & & 9.52 & 87.0 & 36.0 & 0.555 & 0.084 & $0.404-0.698$ & 55.6 & 75.0 \\
\hline Unfavourable/favourable & & 12.75 & & & 0.595 & 0.084 & $0.433-0.734$ & 54.2 & 70.8 \\
\hline \multirow[t]{2}{*}{ Dead/alive } & & 11.62 & 100 & 45.0 & 0.775 & 0.103 & $0.631-0.833$ & 26.7 & 100.00 \\
\hline & Clinically acceptable & & & & & & & & \\
\hline Dead/alive & & 47.1 & 12.5 & 95.0 & 0.775 & 0.103 & $0.631-0.883$ & 33.3 & 84.4 \\
\hline
\end{tabular}

Clinically acceptable corresponds to a specificity of $5 \%$ (ie, that $1 / 20$ salvageable subjects are not treated).

NPV, negative predictive value; PPV, positive predictive value.

defined using the Marshall classification and levels of the biomarkers.

In subjects with GOS 1 at 3 months, initial levels of S-100B were significantly elevated compared with the other GOS levels. In contrast with many reports, we were unable to show that the initial S-100B and NSE values predicted outcome measured as GOS at 3 months or at 12 months post injury. ${ }^{27} 30$ 32-34

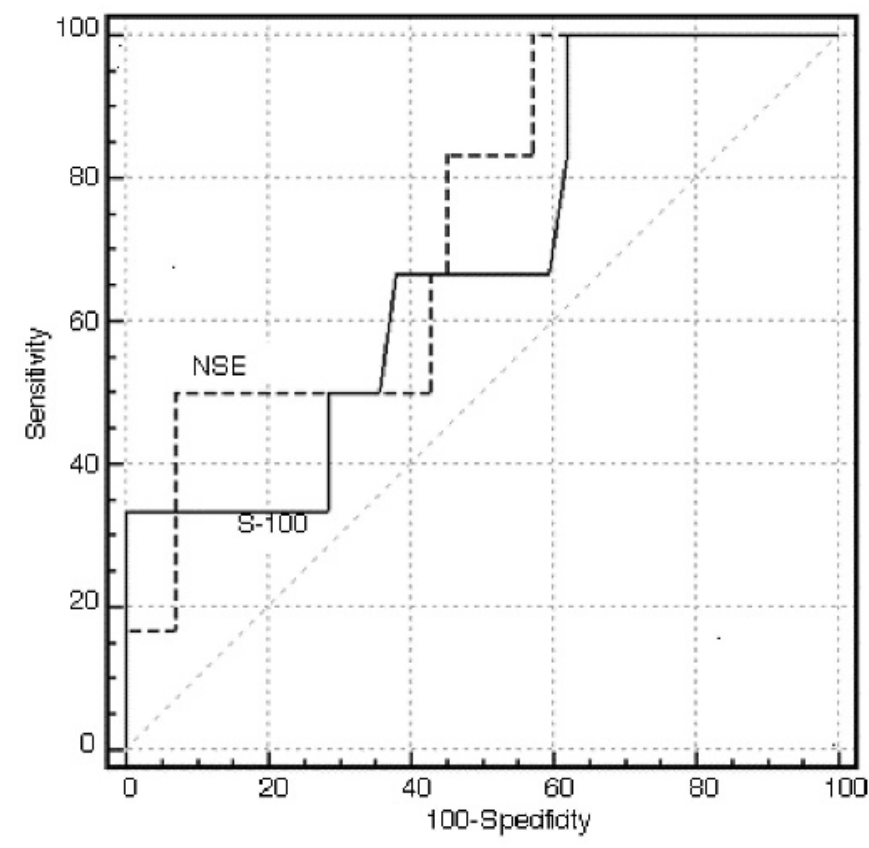

Figure 7 Receiver operated characteristic (ROC) curve analysis of S-100B (AUC 0.687, CI 0.536 to 0.812) and neuron specific enolase (NSE) (AUC $0.734, \mathrm{Cl} 0.587$ to 0.851 ) for the prediction of mortality (Glasgow Outcome Scale 1).
Influencing this finding could be the fact that many of the reports on the prognostic value were based on S-100B levels within $6 \mathrm{~h}$ of injury while our samples were drawn at mean time of $15.6 \mathrm{~h}$. We therefore calculated the initial S-100B level by using a half-time of $240 \mathrm{~min}$. We then used this value in an ROC curve analysis. This did not change our results.

Woertgen et al reported a difference in the primary S-100B value between what they categorised as good and bad outcomes. ${ }^{30}$ They estimated the outcome at discharge and not after 3 months, as recommended in the initial description of GOS. Mortality in their study was $23 \%$ during hospitalisation. Their dichotomisation between good and bad was rather unusual, defining poor as GOS $1-2$ and good as GOS 3-5. This could explain their large difference in mean S-100B in the two groups (4.9 and $1.7 \mu \mathrm{g} / \mathrm{l})$. Furthermore, they did not state what type of treatment protocol was used. Nylén et al found in their analysis of S-100B and its different subunits a significant difference between the maximum levels of S-100B and the subunits studied, and the outcome dichotomised as favourable (GOS 4-5) and unfavourable (GOS 1-3). ${ }^{35}$ Furthermore, the reported levels in their study were on the whole rather low. It has been stated that peak S-100B levels above $2 \mu \mathrm{g} / \mathrm{l}$ would be a good predictor of unfavourable outcome. ${ }^{27}$ These authors chose or selected to study the maximum value instead of the initial value. In our opinion, the value of using a maximum value for prediction of outcome is limited if early prediction is the goal. In our material, four subjects had a peak value of more than $2 \mu \mathrm{g} / \mathrm{l}$. In three of these the first sample exceeded this level. Among these four subjects, two were deceased at 3 months and two had a favourable outcome.

The same pattern holds through for the initial NSE level which is only significantly elevated in GCS 3 and GOS 1 compared with GCS 4-8 and GOS 2-5, respectively. The longer half-time of NSE should make the time of sampling in relation to the injury less sensitive. Previous reports have stated a 
correlation between NSE level and GCS and GOS. ${ }^{36}$ The treatments used in these reports were not always reported and those that were reported followed other treatment guidelines than those used in the present study. The treatment used in this cohort, which showed rather good results in initially severely ill subjects, could be an explanation for the poor prognostic value of S-100B and NSE.

Most studies of S-100B and NSE have assessed the use of these markers in mild and moderate head injury to discriminate between subjects who have to be admitted for observation because of a significant risk of having or developing serious consequences of their head trauma (eg, contusions, epidural haematomas) and those who can be released home, not having a significant risk of developing later complications. ${ }^{37}$ In the treatment of severe head injury, the first goal for the use of a biochemical marker would be to discriminate between subjects who will die irrespective of treatment and those who have a chance of survival, irrespective of outcome. Following this reasoning, the limitation of a test for fatal outcome would be specificity (ie, the number of false positives - subjects not receiving treatment although they were salvageable). Our study clearly shows that the prognostic value of S-100B and NSE for the prediction of clinical outcome defined as dead (GOS 1) is low. A specificity value of $95 \%$ (ie, a false positive rate of $5 \%$ for the cut-off level of S-100B and NSE, $1.67 \mu \mathrm{g} / 1$ and $47.1 \mu \mathrm{g} / \mathrm{l}$, respectively) would result in sensitivity values of the test of $33.3 \%$ and $16.7 \%$, respectively. We would therefore state that in the practical clinical setting, the markers do not allow for the decision of whether or not to treat. Our findings are partly supported by those of Nylén and colleagues. ${ }^{35}$ They analysed the area under the curve and found, in contrast with us, a correlation between the level of S-100B and outcome, dichotomised as unfavourable. They did not state which S-100B value they used in the analysis. They found a significant correlation, although weak. Using their analysis, the conclusion must be that the correlation is not strong enough to be used for prediction or decisions in the clinical setting. Undén et al studied the usefulness of daily S-100B samples for the prediction of secondary complications during treatment of subjects on a neurointensive care unit. They found that the daily values were associated with secondary injuries but not with outcome. They also found that S-100B levels did not predict for the observed secondary complications. ${ }^{38}$ Finally, we were unable to show that one of the markers was superior to the other as a predictor of outcome. The reason for the lack of prognostic value of the brain injury markers in the present study can only be speculated. One of the reasons could be the low mortality $(12.5 \%$ (4.2\% during ICU time)) among our severely injured subjects.

\section{CONCLUSIONS}

This is, to our best knowledge, the first prospective study of S$100 \mathrm{~B}$ and NSE in subjects with sTBI, treated with a strict protocol guided ICP targeted therapy based on the "Lund concept". In this study, we showed that sTBI elicits an elevation above normal values of the biochemical brain injury markers S-100B and NSE. This elevation declines over time towards normal values. There is a correlation between the markers and death. From our results, the markers had no value in the prediction of death or a lesser outcome in our study cohort, irrespective of the time point used for outcome evaluation. There was no difference between the markers with regard to their prognostic value. The treatment protocol used did yield a high number of favourable outcomes and a low mortality at 3 and 12 months post injury. Secondary elevations of the markers during treatment in the ICU did not correlate or predict poor outcome.

Acknowledgements: We are grateful to Ann-Margret Kallberg at Sangtech Medical for help with the analysis of the biochemical markers. We thank our dedicated research nurses Kristin Nyman and Anna-Lena Östlund for their help. We also thank the staff at the neurosurgical department and the intensive care unit.

Funding: This study was financially supported by the Department of Clinical Neurosciences, University Hospital Research Found, Tore Nilsson Foundation, Kempe Foundation and Capio Research Foundation.

Competing interests: None.

Ethics approval: The study was approved by the local ethics committee at Umeå University Hospital (dnr 00-175).

Provenance and peer review: Not commissioned; externally peer reviewed.

\section{REFERENCES}

1. Rabow L, Hedman G. CKBB-isoenzymes as a sign of cerebral injury. Acta Neurochir Suppl (Wien) 1979;28:108-12.

2. Rabow L, Hedman G. Creatine kinaseBB-activity after head trauma related to outcome. Acta Neurochir (Wien) 1985;76:137-9.

3. Ingebrigtsen T, Romner B, Marup-Jensen S, et al. The clinical value of serum S-100 protein measurements in minor head injury: a Scandinavian multicentre study. Brain Inj 2000;14:1047-55.

4. Raabe A, Grolms C, Keller M, et al. Correlation of computed tomography findings and serum brain damage markers following severe head injury. Acta Neurochir (Wien) 1998;140:787-91.

5. Romner B, Ingebrigtsen T, Kongstad P, et al. Traumatic brain damage: serum S-100 protein measurements related to neuroradiological findings. J Neurotrauma 2000;17:641-7.

6. Ingebrigtsen T, Waterloo K, Jacobsen EA, et al. Traumatic brain damage in minor head injury: relation of serum S-100 protein measurements to magnetic resonance imaging and neurobehavioral outcome. Neurosurgery 1999;45:468-75.

7. Waterloo K, Ingebrigtsen T, Romner B. Neuropsychological function in patients with increased serum levels of protein S-100 after minor head injury. Acta Neurochir (Wien) 1997;139:26-31

8. Donato R. S100: a multigenic family of calcium-modulated proteins of the EF-hand type with intracellular and extracellular functional roles. Int J Biochem Cell Biol 2001;33:637-68.

9. Donato R. Intracellular and extracellular roles of $\mathbf{S 1 0 0}$ proteins. Microsc Res Tech 2003;60:540-51.

10. Missler U, Wiesmann M, Friedrich C, et al. S-100 protein and neuron-specific enolase concentrations in blood as indicators of infarction volume and prognosis in acute ischemic stroke. Stroke 1997;28:1956-60.

11. Persson L, Hardemark HG, Gustafsson J, et al. S-100 protein and neuron-specific enolase in cerebrospinal fluid and serum: markers of cell damage in human central nervous system. Stroke 1987;18:911-18.

12. Anderson RE, Hansson LO, Nilsson 0, et al. High serum S100B levels for trauma patients without head injuries. Neurosurgery 2001;48:1255-8.

13. Anderson RE, Hansson LO, Nilsson 0, et al. Increase in serum S100A1-B and S100BB during cardiac surgery arises from extracerebral sources. Ann Thorac Surg 2001;71:1512-17.

14. Unden J, Bellner J, Astrand R, et al. Serum S100B levels in patients with epidural haematomas. Br J Neurosurg 2005;19:43-5.

15. Jonsson $\mathbf{H}$, Johnsson $\mathbf{P}$, Hoglund $\mathrm{P}$, et al. Elimination of $\mathrm{S} 100 \mathrm{~B}$ and renal function after cardiac surgery. J Cardiothorac Vasc Anesth 2000;14:698-701.

16. Ytrebo LM, Nedredal Gl, Korvald C, et al. Renal elimination of protein S-100beta in pigs with acute encephalopathy. Scand J Clin Lab Invest 2001;61:217-25.

17. Townend W, Dibble C, Abid K, et al. Rapid elimination of protein S-100B from serum after minor head trauma. J Neurotrauma 2006;23:149-55.

18. Usui A, Kato K, Abe T, et al. S-100ao protein in blood and urine during open-heart surgery. Clin Chem 1989;35:1942-4.

19. Johnsson $\mathbf{P}$, Blomquist $\mathbf{S}$, Luhrs $\mathbf{C}$, et al. Neuron-specific enolase increases in plasma during and immediately after extracorporeal circulation. Ann Thorac Surg 2000;69:750-4.

20. Olivecrona $\mathbf{M}$, Rodling-Wahlstrom M, Naredi $\mathbf{S}$, et al. Prostacylin treatment in severe traumatic brain injury: a microdialysis and outcome study. J Neurotrauma 2009;26:1251-62.

21. Olivecrona $\mathbf{M}$, Zetterlund $\mathbf{B}$, Rodling-Wahlstrom $\mathbf{M}$, et al. Absence of electroencephalographic seizure activity in patients treated for head injury with an intracranial pressure-targeted therapy. J Neurosurg 2009;110:300-5.

22. Olivecrona M, Rodling-Wahlstrom M, Naredi S, et al. Effective ICP reduction by decompressive craniectomy in patients with severe traumatic brain injury treated by an ICP-targeted therapy. J Neurotrauma 2007;24:927-35.

23. Asgeirsson B, Grande PO, Nordstrom $\mathrm{CH}$. A new therapy of post-trauma brain oedema based on haemodynamic principles for brain volume regulation. Intensive Care Med 1994;20:260-7.

24. Koskinen L0, Olivecrona M. Clinical experience with the intraparenchymal intracranial pressure monitoring Codman MicroSensor system. Neurosurgery 2005;56:693-8. 
25. Nygaard O, Langbakk B, Romner B. Neuron-specific enolase concentrations in serum and cerebrospinal fluid in patients with no previous history of neurological disorder. Scand J Clin Lab Invest 1998;58:183-6.

26. Stalnacke BM, Bjornstig U, Karlsson K, et al. One-year follow-up of mild traumatic brain injury: post-concussion symptoms, disabilities and life satisfaction in relation to serum levels of S-100B and neurone-specific enolase in acute phase. J Rehabil Med 2005;37:300-5.

27. Raabe A, Grolms C, Sorge 0, et al. Serum S-100B protein in severe head injury. Neurosurgery 1999;45:477-83.

28. Kanner AA, Marchi N, Fazio V, et al. Serum S100beta: a noninvasive marker of blood-brain barrier function and brain lesions. Cancer 2003;97:2806-13.

29. Marchi N, Rasmussen P, Kapural M, et al. Peripheral markers of brain damage and blood-brain barrier dysfunction. Restor Neurol Neurosci 2003;21:109-21.

30. Woertgen C, Rothoerl RD, Holzschuh M, et al. Comparison of serial S-100 and NSE serum measurements after severe head injury. Acta Neurochir (Wien) 1997;139:1161-4.

31. Ytrebo LM, Ingebrigtsen T, Nedredal Gl, et al. Protein S-100beta: a biochemical marker for increased intracranial pressure in pigs with acute hepatic failure. Scand J Gastroenterol 2000;35:546-51.
32. Raabe A, Grolms C, Seifert V. Serum markers of brain damage and outcome prediction in patients after severe head injury. Br J Neurosurg 1999;13:56-9.

33. Rothoerl RD, Woertgen C, Brawanski A. S-100 serum levels and outcome after severe head injury. Acta Neurochir Suppl 2000;76:97-100.

34. Vos PE, Lamers KJ, Hendriks JC, et al. Glial and neuronal proteins in serum predict outcome after severe traumatic brain injury. Neurology 2004;62:1303-10.

35. Nylén K, Ost M, Csajbok LZ, et al. Serum levels of S100B, S100A1B and S100BB are all related to outcome after severe traumatic brain injury. Acta Neurochir (Wien) 2008;150:221-7.

36. Herrmann M, Curio N, Jost S, et al. Protein S-100B and neuron specific enolase as early neurobiochemical markers of the severity of traumatic brain injury. Restor Neurol Neurosci 1999;14:109-14.

37. Unden J, Bellner J, Eneroth $\mathrm{M}$, et al. Raised serum S100B levels after acute bone fractures without cerebral injury. J Trauma 2005;58:59-61.

38. Undén J, Astrand R, Waterloo K, et al. Clinical significance of serum S100B levels in neurointensive care. Neurocrit Care 2007;6:94-9.

39. Marshall LF, Marshall SB, Klauber MR, et al. A new classification of head injury based on computerized tomography. J Neurosurg 1991;75:S14-20.

\section{Stay a step ahead with Online First}

We publish all our original articles online before they appear in a print issue. This means that the latest clinical research papers go straight from acceptance to your browser, keeping you at the cutting edge of medicine. We update the site weekly so that it remains as topical as possible. Follow the Online First link on the home page and read the latest research. 